\title{
Precipitable Water Vapor Estimates in the Australian Region from Ground-Based GPS Observations
}

\author{
Suelynn Choy, ${ }^{1}$ Chuan-Sheng Wang, ${ }^{1,2,3}$ Ta-Kang Yeh, ${ }^{2}$ John Dawson, \\ Minghai Jia, ${ }^{4}$ and Yuriy Kuleshov ${ }^{1,5}$ \\ ${ }^{1}$ RMIT University, Melbourne, VIC 3001, Australia \\ ${ }^{2}$ National Taipei University, New Taipei City 237, Taiwan \\ ${ }^{3}$ Green Environment Engineering Consultant (GEEC) Co., Ltd., Chutung, Hsinchu County 31040, Taiwan \\ ${ }^{4}$ Geoscience Australia, Canberra, ACT 2609, Australia \\ ${ }^{5}$ Australian Bureau of Meteorology, Melbourne, VIC 3008, Australia
}

Correspondence should be addressed to Suelynn Choy; suelynn.choy@rmit.edu.au

Received 8 November 2014; Revised 12 February 2015; Accepted 16 March 2015

Academic Editor: Ismail Gultepe

Copyright (C) 2015 Suelynn Choy et al. This is an open access article distributed under the Creative Commons Attribution License, which permits unrestricted use, distribution, and reproduction in any medium, provided the original work is properly cited.

\begin{abstract}
We present a comparison of atmospheric precipitable water vapor (PWV) derived from ground-based global positioning system (GPS) receiver with traditional radiosonde measurement and very long baseline interferometry (VLBI) technique for a five-year period (2008-2012) using Australian GPS stations. These stations were selectively chosen to provide a representative regional distribution of sites while ensuring conventional meteorological observations were available. Good agreement of PWV estimates was found between GPS and VLBI comparison with a mean difference of less than $1 \mathrm{~mm}$ and standard deviation of $3.5 \mathrm{~mm}$ and a mean difference and standard deviation of $0.1 \mathrm{~mm}$ and $4.0 \mathrm{~mm}$, respectively, between GPS and radiosonde measurements. Systematic errors have also been discovered during the course of this study, which highlights the benefit of using GPS as a supplementary atmospheric PWV sensor and calibration system. The selected eight GPS sites sample different climates across Australia covering an area of approximately $30^{\circ} \mathrm{NS} / \mathrm{EW}$. It has also shown that the magnitude and variation of PWV estimates depend on the amount of moisture in the atmosphere, which is a function of season, topography, and other regional climate conditions.
\end{abstract}

\section{Introduction}

Water vapor is the most abundant greenhouse gas in the atmosphere [1] generating more greenhouse effects on our planet than any other single gas such as carbon dioxide. Many scientific reports in recent years have highlighted and validated the role of water vapor as a critical component of the greenhouse gases driving global weather and climate changes [2-4]. However, water vapor content makes up only $5 \%$ of the air and is highly variable in its distribution; that is, it fluctuates seasonally and regionally. This makes water vapor difficult to measure and observe. In fact, water vapor content is one of the poorest observed atmospheric parameters, both spatially and temporally. From a climatic perspective, accurate, and consistent observations of the atmospheric water vapor content over extended periods of time are fundamental to provide the initial conditions required for climate models.
Observations of atmospheric humidity have traditionally been made using radio soundings, for example, balloonborne radiosondes, to study water vapor variability and trends [5-7]. Satellite observations such as infrared sounders [8] and microwave radiometers [9] have also been used in many studies to quantify water vapor variability and changes $[10,11]$. However these datasets are affected by issues of calibration, poor quality of data, temporal resolution, and long term reliably [12].

Global satellite navigation systems (GNSS) such as the U.S. Global Positioning System (GPS) technology has evolved and emerged as a powerful atmospheric remote sensing tool for providing accurate observations of atmospheric parameters such as water vapor in the troposphere. GPS was originally designed as a military and then civilian positioning and navigation device. In 1992, Bevis et al. [13] were the first to 
devise innovative methods, now known as ground-based GPS meteorology, for retrieving integrated atmospheric water vapor along the GPS signal paths as they propagate through the atmosphere. Geodesists have, for a decade, treated the effects of the atmosphere as noise parameters that need to be removed from the data for the process of estimating positions. However, Bevis et al. [13] proposed that this delay can be parameterized in terms of a time-varying total tropospheric delay. If surface temperature and pressure observations at the GPS receiver are known to sufficient accuracy, tropospheric delay can be converted into accurate estimates of the total zenith column water vapor, termed precipitable water vapor (PWV). Here, PWV means the height of an equivalent column of liquid water from the Earth's surface to the top of the atmosphere (unit: $\mathrm{mm}$ ). About $45-65 \%$ of the PWV is included in the surface-850 hPa layer [5].

More recently it was found that the GPS satellite constellation also allows for radio occultation (RO) observations of the Earth's atmosphere using one or more GPS receivers onboard Low Earth Orbit satellites. These space-based RO observations are a novel atmospheric sensing technique permitting routine profiling of the atmospheric parameters with high vertical resolution and precision based on limb sounding geometry [14-16]. However, the upper stratosphere and lower troposphere are regions of maximum uncertainty when using the GPS RO technique to retrieve atmospheric profiles. This is instigated by the large amount of water vapor in the lower atmosphere, which introduces super-refraction and multipath effects. As such, the ground-based GPS technique is better suited for water vapor retrievals in the lower atmosphere due to its continuous measurements, availability under all weather conditions, high accuracy $(<3 \mathrm{~mm}$ PWV), long-term stability, homogeneity, and low cost [13, 17-21].

This research aims to assess the feasibility of using the GPS ground-based meteorology technique for long-term measurement of PWV and variability in the Australian region to support future climate monitoring studies. Glowacki et al. [22] and Tregoning et al. [20] have previously compared the accuracy of water vapor estimates for the Australian region. However these comparisons were conducted using only short-time spanning observations and "legacy" antenna phase center offset and variation corrections. Numerous studies have highlighted the deficiencies of these processing strategies and models, which significantly impacted the accuracy and precision of the estimated tropospheric delay and PWV [19, 23-25]. In fact observing GPS PWV for climate studies requires a homogenous and long-term time series of data.

The main motivation of this analysis work is to validate the computation strategy used to process GPS data and conversion to PWV estimates given surface pressure and temperature readings. As a first step, we present a regional quantitative analysis of PWV focusing on eight Australian Regional GNSS/GPS Network (ARGN) stations over a fiveyear period (2008-2012). These stations were selectively chosen to provide a representative regional distribution of GPS sites with varying climates while ensuring conventional meteorological observations such as surface-based data are available for PWV conversion and other PWV sensors, for example, upper-air data from radiosondes, for validation purposes. Although the datasets presented herein only cover a short period of time from a climate perspective, the ARGN GNSS stations have been built up progressively since the 1990s, which has potential to provide at least 15 years of GPS derived PWV estimates. The study is divided into three components: (1) estimation of tropospheric ZPD from GPS measurements, (2) conversion of tropospheric ZPD to PWV estimates, and (3) intertechnique comparison of the GPS-derived PWV using radiosonde and very long baseline interferometry (VLBI) measurements. The ultimate goal of this study is to use the data to investigate secular trend and seasonal variation of PWV in Australia and its implications for climate research and applications.

\section{Ground-Based GPS Meteorology}

GPS radio waves are delayed by the neutral atmosphere, which results in a positive bias in the range measurements. This delay is one major error source in GPS processing and is traditionally known as the "tropospheric delay." This error must be dealt with appropriately to achieve precise positioning results. In GPS processing, the tropospheric delay can be computed as zenith path delay (ZPD) (often used interchangeably with "zenith tropospheric delay" abbreviated as ZTD). ZPD is defined as the sum of the hydrostatic (ZHD) caused by the atmospheric gases such as nitrogen, oxygen, argon and carbon dioxide, and nonhydrostatic or wet (ZWD) delays, which is mainly contributed by water vapor contained in the atmosphere, as shown in

$$
\mathrm{ZPD}=\mathrm{ZHD}+\mathrm{ZWD} \text {. }
$$

From ZPD, ZWD can be obtained by subtracting ZHD from ZPD. If the surface pressure $\left(P_{s}\right)$ at the station is known as well as the station latitude $(\emptyset)$ and height $(h)$, ZHD can be computed by

$$
\mathrm{ZHD}=\frac{(2.2768 \pm 0.0005) P_{s}}{1-0.00266 \cos 2 \emptyset-0.00028 h} .
$$

ZHD is generally very stable and is easily determined using an empirical model such as the Hopfield or Saastamoinen models $[26,27]$ and constitutes more than $80 \%$ of the total path delay. ZHD can reach up to about $2.3 \mathrm{~m}$ in the zenith direction and up to $30 \mathrm{~m}$ for a slant path close to the Earth's surface. Given surface pressure measurements, it is usually possible to model and remove the hydrostatic delay with accuracy of a few millimeters or less. On the other hand, the ZWD delay is more spatially and temporally variable and is more difficult to remove than the ZHD. The ZWD can be as small as a few centimeters or less in arid regions and as large as $35 \mathrm{~cm}$ in humid regions [13]. As it is impossible to accurately measure the wet delay from surface meteorological measurements, GPS scientists determine the hydrostatic delay from surface measurements and then attempt to estimate the wet delay as part of the data processing.

ZWD may be converted to PWV via a dimensionless conversion factor $(\Pi)[28]$ :

$$
\mathrm{PWV}=\mathrm{ZWD} \cdot \Pi \text {, }
$$


TABLE 1: GPS tropospheric ZPD computation strategy.

\begin{tabular}{ll}
\hline Software & Bernese GPS Software Version 5.0 \\
\hline Processing method & Relative positioning \\
\hline $\begin{array}{l}\text { Satellite trajectories and earth orientation } \\
\begin{array}{l}\text { Satellite and receiver antenna phase } \\
\text { center calibration }\end{array}\end{array}$ & Best available IGS products \\
\hline Tropospheric model & IGS08 absolute phase center offset and variation model \\
\hline $\begin{array}{l}\text { Tropospheric estimation } \\
\text { Tropospheric mapping function }\end{array}$ & A priori model is the Saastamoinen-based hydrostatic mapped with the dry-Neill \\
\hline Elevation cut-off & $\begin{array}{l}\text { Zenith delay corrections are estimated using the wet-Niell mapping function with a } \\
\text { temporal resolution of } 1 \text { hour. N-S and E-W horizontal gradients are solved. }\end{array}$ \\
\hline
\end{tabular}

where

$$
\Pi^{-1}=10^{-6} \rho R_{v}\left(\frac{k_{3}}{T_{m}}+k_{2}^{\prime}\right) .
$$

Here $k_{2}^{\prime}$ and $k_{3}$ are physical constants, $\rho$ is the density of liquid water, $R_{v}$ is the specific gas constant of water vapour, and $T_{m}$ is the weighted mean temperature of the atmosphere defined by Askne and Nordius [29]. $\Pi$ is approximately 0.150.16 and it may vary by about $20 \%$ depending on the weighted mean temperature [23]. $T_{m}$ can be approximated from station temperature observations $\left(T_{s}\right)$. For the Australian region, $T_{m}$ is computed by Bai [30] using a least square fit of 2493 radiosonde and GPS data pairs as

$$
T_{m} \approx 70.03+0.726 T_{s}
$$

with an RMS scattering of about $3.16 \mathrm{~K}$. Equation (5) is almost similar to the original linear regression equation derived by Bevis et al. [13]. The main uncertainty when converting ZWD to PWV is the estimation of the weighted mean temperature of the troposphere. However, the GPS $\mathrm{PWV}$ is quite robust against the uncertainties; that is, a mean temperature uncertainty of $5 \mathrm{~K}$ is related to $1.7-2.9 \%$ in the PWV estimates [31]. It is also worthwhile to note that it is possible to use the derived GPS-ZWD as an indicator of atmospheric water content, which has proved millimeter accuracy when compared to traditional atmospheric sensing methods such as radiosondes and water vapor radiometers $[13,17,20,21,32]$.

2.1. GPS Processing Strategy. In recent years, GPS processing strategies and models have progressively advanced particularly in the development of GPS satellite and receiver absolute antenna phase center offsets and variations (absolute PCOs and PCVs) [23]. This has enabled more accurate and precise estimation of GPS heights and the highly correlated estimates of ZPD [33, 34]. Furthermore, the introduction of absolute PCOs and PCVs in GPS processing has also improved the temporal consistency and homogeneity of ZPD time series $[19,23,35,36]$, which is essential for identification of climate trends.

In this study, the processing of the ZPD estimation was carried out at Geoscience Australia (GA) using the in-house Bernese GNSS Software Version 5.0 [37]. The processing

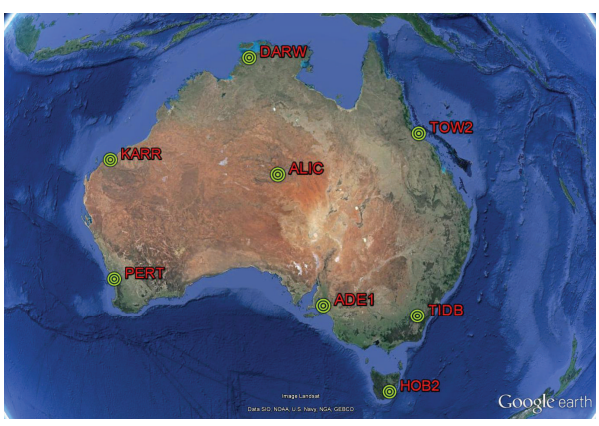

FIgURE 1: A Google Earth map showing locations of the eight Australian GNSS sites used in the study. ADE1: Adelaide, ALIC: Alice Springs, DARW: Darwin, HOB2: Hobart; KARR: Karratha, PERT: Perth, TIDB: Tidbinbilla, and TOW2: Townsville.

method was based on "network" approach that is relative positioning technique, that is, using double-differenced phase observations. Station coordinates were estimated on a daily basis and constrained tightly to their ITRF2008 values to reduce the correlation between the estimated station coordinates and tropospheric parameters. The computation strategy complies with the International Earth Rotation and Reference Systems Service Convention and the current IGS analysis standards. See Table 1 for a summary of the current GA GPS processing strategy.

\subsection{GPS Stations Selection and ZPD Comparison. Daily GPS} data from eight ARGN stations from 2008 to 2012 were processed as part of a network of 20 Australian GNSS stations. The eight stations were selectively chosen to provide a representative regional distribution of GPS sites on the Australian continent while ensuring good quality conventional meteorological observations, for example, surfacebased temperature and pressure data, are available for PWV conversion, and other PWV sensors, for example, upper-air data from radiosondes and VLBI are available for validation. Locations of the eight continuously operating GNSS stations used are depicted in Figure 1.

To validate the accuracy of the ZPD computed from GA, the estimates were compared to the International GNSS Service (IGS) Final ZPD products generated by United States Naval Observatory (USNO) [38]. UNSO has officially, since 
TABLE 2: Average differences $(\mathrm{mm})$ between the computed ZPD estimates from GA and USNO for 2011. Note that no GPS data were recorded at ADE1 in 2011.

\begin{tabular}{lccc}
\hline Site ID & Mean $(\mathrm{mm})$ & STD $(\mathrm{mm})$ & Number of counts \\
\hline ADE1 & - & - & - \\
ALIC & 1.5 & 3.7 & 2993 \\
DARW & 3.6 & 4.0 & 2481 \\
HOB2 & 0.9 & 3.8 & 2340 \\
KARR & 1.8 & 3.0 & 3186 \\
PERT & 0.0 & 3.7 & 3259 \\
TIDB & -0.7 & 3.3 & 3243 \\
TOW2 & 1.5 & 3.8 & 2350 \\
Average & 1.2 & 3.6 & 2836 \\
\hline
\end{tabular}

July 2011, made the transition from Jet Propulsion Laboratory (JPL) as the IGS Final tropospheric products provider. The ZPD products are produced routinely from a PPP processing method using the Bernese GNSS Software Version 5.0 [39]. However, a different mapping function, that is, global mapping function (GMF), and elevation cut-off angle $\left(7^{\circ}\right)$ are adopted by USNO. Note that GA GNSS processing uses the Niell Mapping Function and a $10^{\circ}$ elevation cut-off angle. The IGS final tropospheric products have a temporal resolution of 5 minutes and with an accuracy level of $4 \mathrm{~mm}$ [39]. The statistical results for the 2011 comparison are shown in Table 2 along with the number of records being compared. The statistics were computed based on the differences between the GA and IGS estimates, that is, GA minus IGS. A comparison was made when there was an epoch match between GA and UNSO ZPD records. Note that GA ZPD values are computed on an hourly basis while USNO provides ZPD estimates with a sampling interval of 5 minutes. No interpolation was made for comparison.

The ZPD estimates from GA are quite consistent to those of UNSO with an average standard deviation of $3.6 \mathrm{~mm}$, indicating that both techniques provide estimates of comparable accuracy. This level of agreement aligns with previously published results by UNSO comparing PPP derived tropospheric ZPD with JPL's "network" approach [39]. The different processing strategies and mapping functions used by the GA and UNSO in computing ZPD may explain the small variations between the two products.

\section{PWV Datasets}

3.1. Surface Meteorological Data. To convert GPS derived $\mathrm{ZPD}$ to PWV, accurate pressure and temperature observations are required at the GPS sites. The ideal situation is to have meteorological sensors installed adjacent to the GPS antenna for accurate PWV estimation. As most Australian GPS sites are historically established for geodetic and geodynamic purposes, they are not often equipped with good quality and calibrated meteorological instruments. One method to overcome this is to apply an interpolation or extrapolation technique using surface pressure and temperature recordings from automatic weather station (AWS) nearest
TABLE 3: Approximate lateral distances $(\mathrm{km})$ and height differences (m) between the GPS and AWS sites.

\begin{tabular}{lccc}
\hline GPS site ID & AWS ID & $\begin{array}{c}\text { GPS-AWS, } \\
\text { lateral }(\mathrm{km})\end{array}$ & $\begin{array}{c}\text { GPS-AWS, } \\
\text { Height }(\mathrm{m})\end{array}$ \\
\hline ADE1 & 23034 & 27 & 25.2 \\
ALIC & 15590 & 15 & 41.4 \\
DARW & 14015 & 55 & 38.8 \\
HOB2 & 94008 & 7 & 17.3 \\
KARR & 4083 & 45 & 110.2 \\
PERT & 9021 & 17 & 25.0 \\
TIDB & 70351 & 22 & 69.2 \\
TOW2 & 32040 & 29 & 20.2 \\
\hline
\end{tabular}

to each GPS site, that is, lateral separation distance of less than $50 \mathrm{~km}$. Three-hour pressure and temperature recordings were obtained from the Australian Bureau of Meteorology (BOM) Data Archive for Meteorology. Although the data were provided at 3-hour interval, the data was linearly interpolated to 1 hour interval in order to match the GPSPWV estimation sampling interval. Table 3 summarizes the approximate lateral distances and height differences between the GPS and AWS sites.

Although theoretically one should consider the effects of both lateral separation and height differences between the GPS and AWS sites, the vertical variability of pressure and temperature is more sensitive to height than the lateral separation between them. Thus, the height difference between the GPS and weather stations is more important in the computation process than the geographical positions. Gutman et al. [40] concluded that the weather stations within $50 \mathrm{~km}$ of a GPS station can be used to derive surface pressure at the GPS site with about $0.5 \mathrm{hPa}$ bias. An error of $0.5 \mathrm{hPa}$ in the pressure measurement will cause an error of $1 \mathrm{~mm}$ in the estimated ZWD [41] and subsequently an error in the PWV estimates of about $0.2 \mathrm{~mm}$ [31].

In this work, the method used to map pressure data collected at the nearest AWS to the GPS site is adopted from the World Meteorological Organization [42]. Firstly, the pressure recordings at the AWS level are converted to a common reference level, which is often the mean sea level (MSL), and secondly, the parameters at the MSL are then interpolated to deduce pressure values at the altitude of the GPS stations. The BOM AWS generally provides pressure values both on surface level and at the MSL, while the temperature values are recorded at surface level. The pressure values are corrected for the vertical height difference using the barometric formula [43]. However no correction is applied to surface temperature. This is because for a maximum height difference of $110 \mathrm{~m}$ at KARR, for example, which has the largest height difference of all the stations used, the uncertainty in temperature is about $0.72 \mathrm{~K}$ (according to the standard atmospheric lapse rate of $0.00065 \mathrm{~K} / \mathrm{m}$ ). This will have minimal effect on the PWV estimation error. Therefore, surface temperature from the AWS is applied directly in (5). 
TABLE 4: Approximate lateral distances $(\mathrm{km})$ and height differences $(\mathrm{m})$ between the GPS and radiosonde (RS) sites.

\begin{tabular}{lccc}
\hline GPS site ID & RS ID & $\begin{array}{c}\text { GPS-RS, } \\
\text { lateral }(\mathrm{km})\end{array}$ & $\begin{array}{c}\text { GPS-RS, } \\
\text { height }(\mathrm{m})\end{array}$ \\
\hline ADE1 & 23034 & 27 & 25.2 \\
ALIC & 15590 & 15 & 41.4 \\
DARW & 14015 & 55 & 38.8 \\
HOB2 & 94008 & 7 & 17.3 \\
KARR $^{*}$ & 4032 & 173 & 107.1 \\
PERT & 9021 & 17 & 25.0 \\
TIDB & 72150 & 141 & 433.3 \\
TOW2 & 32040 & 29 & 20.2 \\
\hline
\end{tabular}

3.2. Upper Air Soundings: Radiosonde Data. Radiosondes are the primary operational source of upper air observations including temperature, pressure, and moisture. Radiosonde flights are generally released twice a day (e.g., 11:00 UTC and 23:00 UTC). A radiosonde flight ascends to $2 \mathrm{~km}$ in 78 minutes and reaches $5 \mathrm{~km}$ in about 20 minutes after the launch. Although radiosondes can provide meteorological observations with good vertical resolution, the temporal and spatial variability of atmospheric humidity measurements are not significant. Furthermore, the usefulness of radiosonde data for long-term climate monitoring is limited by errors and biases associated with changes in instrument and data processing procedures over time [21]. Nevertheless they remain a source of independent validation data and are often used as a source of information for validating GPS-PWV datasets. Radiosonde data were obtained for the following sites: ADE1, ALIC, DARW, KARR, HOB2, PERT, TIDB, and TOW2 from the Australian BOM. The approximate lateral distances and height differences between the GPS and radiosonde sites are listed in Table 4 . Note that the nearest radiosonde stations to KARR and TIDB GPS sites are different from the AWS sites hence marked with an asterisk $(*)$ to highlight the differences between Tables 3 and 4. The radiosonde instruments in use at these sites during the investigation period are the Vaisala RS92-K. The Vaisala RS92-K with a capacitive sensor is known to suffer from a dry bias in relative humidity of about $1.2 \mathrm{~mm}$ PWV [21], which can contribute to the uncertainly when comparing between measurements of PWV to radiosonde.

Assuming the water vapor density variation in each layer is linear, the estimation of column integrated PWV along the path of the radiosonde sounding balloon can be approximated by

$$
\mathrm{PWV}=\frac{1}{\rho} \frac{\sum\left(h_{j+1}-h_{j}\right) \cdot\left(\rho_{v}^{j+1}+\rho_{v}^{j}\right)}{2},
$$

where $h$ is the height of the sounding, $\rho_{v}$ is the density of water vapor, and the subscript and superscript $j+1$ and $j$ denote the top and bottom of each layer for height and water vapor density. The density of water vapor can be computed from

$$
\rho_{v}=\frac{P_{v}}{R_{v} \cdot T} .
$$

3.3. Very Long Baseline Interferometry (VLBI). VLBI is a type of astronomical interferometry used in radioastronomy to measure the position of the Earth and its orientation in space. Like GPS and other space geodetic techniques, VLBI technique also requires modeling the propagation of radio wave signals through the neutral part of the atmosphere and correcting for the error. Thus VLBI can be used as an independent source, in addition to radiosonde or water vapor radiometer, to assess the quality of the GPS derived atmospheric information. The International VLBI Service for Geodesy and Astrometry (IVS) provides tropospheric products since 2002 [44].

The Australian Long Baseline Array is part of the Australia Telescope National Facility. It consists of VLBI antennas mainly located on the Australian continent, with a few antennas in New Zealand and Africa. In this study, two Hobart VLBI telescopes were used for comparison between GPS derived PWV and radiosonde. The new Hobart $12 \mathrm{~m}$ telescope (HOBS12) is colocated with an existing $26 \mathrm{~m}$ telescope (HOBS26) that has collected more than 20 years of VLBI time series [45]. Located midway between the $12 \mathrm{~m}$ and $26 \mathrm{~m}$ telescopes is the HOB2 GPS station, which is ideal to compare and validate the estimation of ZWD. In this case, similar mapping function was used to ensure consistency between the two datasets. VLBI and GPS processing use different software strategies, and it is reasonable to expect small discrepancies between the two solutions. VLBI-PWV time series could also be computed if surface meteorological data is available.

\section{PWV Comparison Results}

4.1. Hobart: GPS, VLBI, and Radiosonde. Figure 2 shows PWV time series from 2010 to 2012 at Hobart GPS and VLBI colocated sites. Also plotted in the time series are the PWV estimates from a radiosonde sites located at Hobart Airport situated $7 \mathrm{~km}$ away from the geodetic stations. The annual variation in PWV estimates using the three different techniques is quite similar as presented in Figure 2.

In evaluating the intertechnique biases, radiosonde should not in any way be assumed to provide the "truth" as it has been recognized in the literature as having its own systematic bias of about $1.2 \mathrm{~mm}$ depending on the types of radiosonde $[19,21,22,30,36,46]$. Unless the bias is accurately known which is difficult to assess and calibrated, any validation work against radiosonde will not be better than this level. Nevertheless radiosonde measurements of PWV are traditionally and often used to evaluate the quality of PWV estimates derived from GPS and VLBI as well as other meteorological sensors. Radiosonde observations are chosen as the basis against which the GPS estimates are compared to. Figure 3 shows the differences between radiosonde PWV against GPS, that is, "radiosonde minus GPS." As the radiosonde flights were launched once or twice a day (mostly for Hobart upper air station), the statistical comparison was only done for the same matching epoch; that is, no interpolation was applied. There were a total of 2141 observations compared over the 3-year period. The 

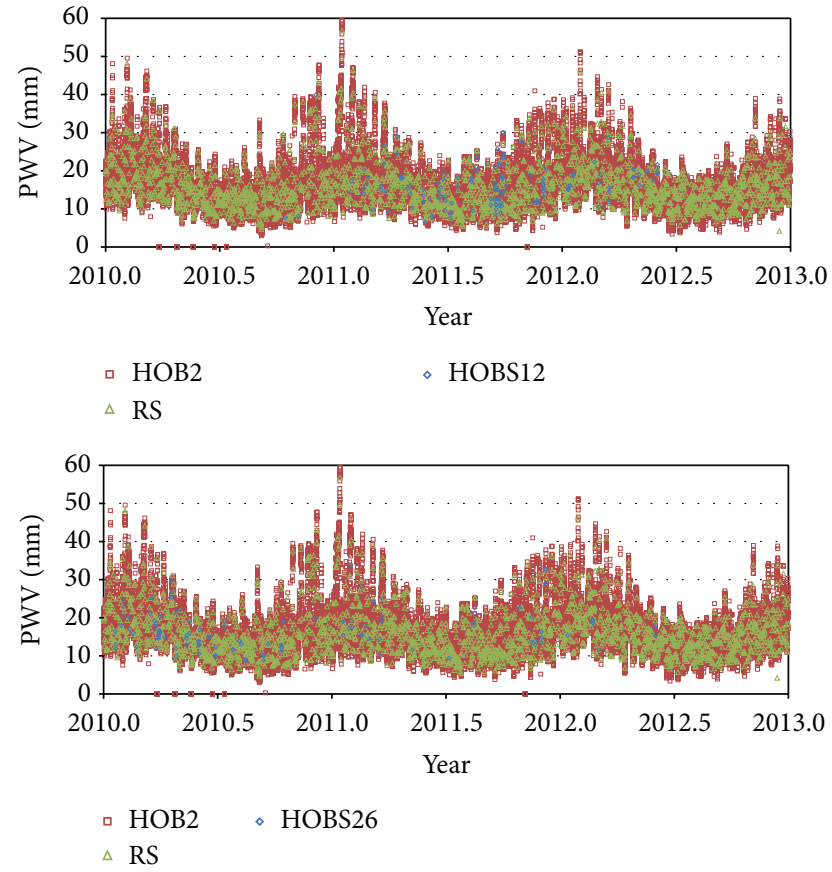

FIgURE 2: PWV time series at colocated GPS (square) and VLBI (diamond) sites in Hobart, Australia. A radiosonde station (triangle) is also present in Hobart Airport located approximately $7 \mathrm{~km}$ away from the Hobart geodetic site.

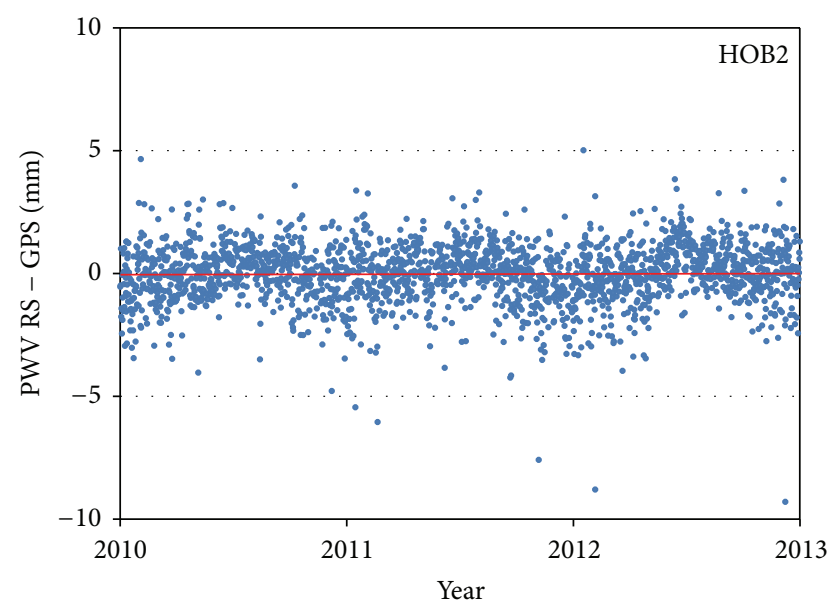

FIgURE 3: PWV differences $(\mathrm{mm})$ between radiosonde and GPS estimates. Positive values indicate that the radiosonde observations are "more moist" than GPS. A fitted linear regression line is denoted by the red solid line and is close to zero.

differences between radiosonde and GPS have a mean value close to zero and a standard deviation of $1.3 \mathrm{~mm}$. These results match those reported by $[20-22,30]$. This demonstrates that GPS and radiosonde PWV measurements show a high level of agreement with little biases, in which case GPS PWV data can be used to validate VLBI measurements of PWV.
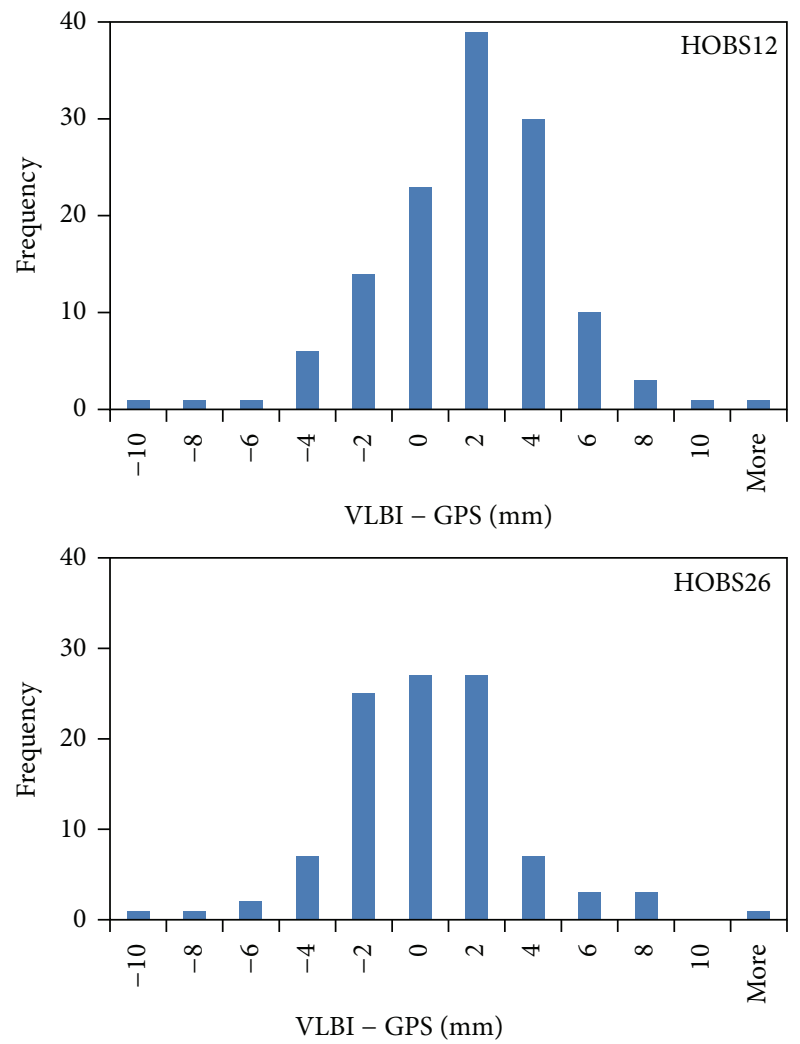

FIGURE 4: Histograms of PWV differences between VLBI and GPS estimates.

TABLE 5: Mean and standard deviation $(\mathrm{mm})$ of the differences between VLBI and GPS derived PWV estimates.

\begin{tabular}{lcccc}
\hline PWV & $\begin{array}{c}\text { Mean } \\
(\mathrm{mm})\end{array}$ & $\begin{array}{c}\text { STD } \\
(\mathrm{mm})\end{array}$ & $\begin{array}{c}\text { Number of } \\
\text { counts }\end{array}$ & $\begin{array}{c}\text { Height } \\
\text { difference } \\
(\mathrm{m})\end{array}$ \\
\hline HOBS12 - HOB2 & 0.7 & 3.5 & 130 & 3.7 \\
HOBS26 - HOB2 & -0.6 & 3.3 & 104 & 20.4 \\
\hline
\end{tabular}

Comparison between GPS and VLBI derived PWV was not a straightforward procedure. The VLBI available data was irregularly spaced due to scheduling irregularities. Therefore, the epoch between the VLBI and GPS data needed to be matched in order for the comparison to be meaningful. It was also decided that no interpolation to the measurement epochs should be undertaken to ensure that the best comparison results were made. Therefore epochs without such GPS PWV estimates were not used in the analysis. This reduced the number of PWV measurements to 130 for HOBS12 and 104 for HOBS26. Table 5 presents the mean and standard deviation values of the differences between VLBI and GPS PWV estimates. HOBS12 and HOBS26 have a mean difference of less than $1 \mathrm{~mm}$ and standard deviation of about $3.5 \mathrm{~mm}$. These results agree favorably with previous VLBI and GPS PWV estimates comparatives studies carried out by Jin and Luo [17]. Figure 4 shows histogram distribution of the PWV differences for HOBS12 and HOBS26. 

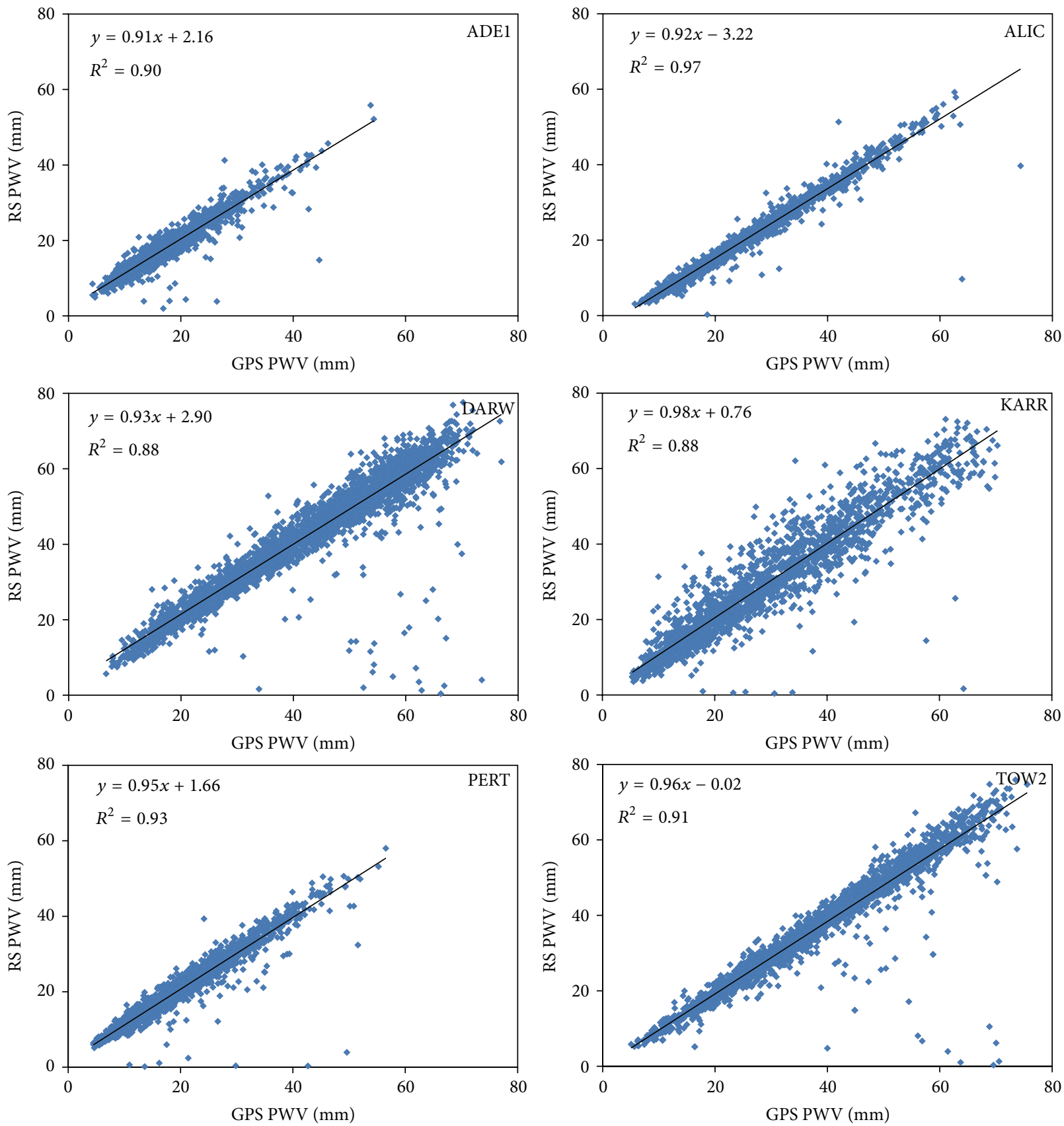

FIGURE 5: Scatterplots of GPS versus radiosonde measurements of PWV.

4.2. Australian Regional GNSS Stations: GPS and Radiosonde. Estimates of GPS derived PWV and radiosonde measurements of PWV were compared over the 5-year period. It was discovered during the course of this study that the radiosonde readings at Tidbinbilla (TIDB) were providing spurious measurements. This could be an indication that the instrument is out of calibration. Thus the measurements from this site were excluded in the analysis. Also in 2011 and 2012, no GPS data were recorded at ADE1 GPS station.

Figure 5 shows scatterplots of PWV estimates from GPS versus radiosonde measurements, while Table 6 lists the number of comparison records over the period. A comparison was made when there was an exact epoch match between the GPS and radiosonde recordings. Although most radiosonde flights were launched twice a day, the comparison presented herein does not specify the time of the day when the radiosonde data and the impact of daily variations were collected. Also shown in the scatterplots are the correlation coefficient denoted by " $R$ ". In general, GPS and radiosonde PWV estimates show a high level of agreement with correlation coefficients of $\sim 0.88$ or greater. Outliers were present as seen in the plots. They were expected in large datasets 


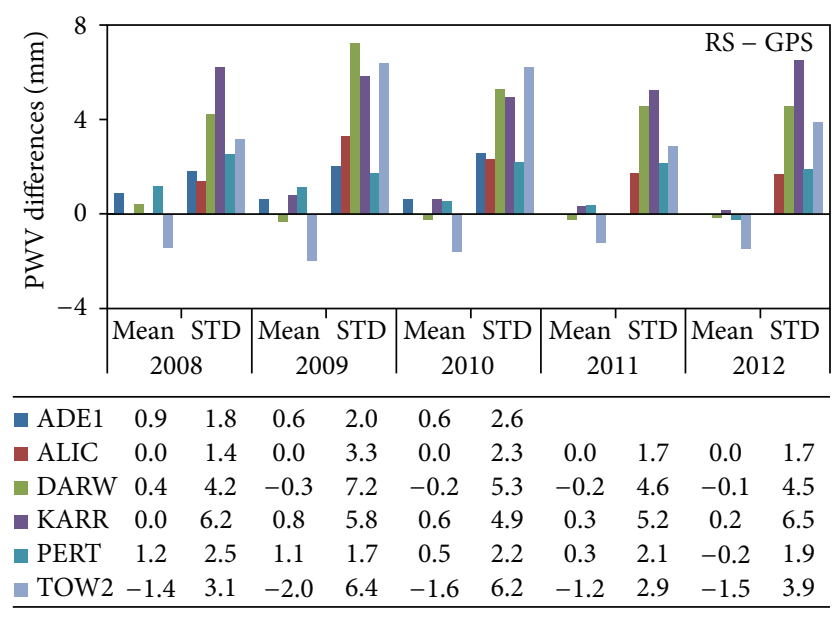

FIGURE 6: Comparison between radiosonde measurements of PWV (mm) and GPS for 2008-2012.

TABLE 6: Number of counts used to compare between GPS-PWV and RS-PWV.

\begin{tabular}{lccccc}
\hline \multirow{2}{*}{ GPS site ID } & \multicolumn{5}{c}{ Number of counts } \\
& 2008 & 2009 & 2010 & 2011 & 2012 \\
\hline ADE1 & 738 & 742 & 525 & - & - \\
ALIC & 332 & 354 & 389 & 362 & 268 \\
DARW & 626 & 692 & 718 & 702 & 747 \\
KARR & 417 & 380 & 488 & 410 & 312 \\
PERT & 756 & 756 & 741 & 768 & 154 \\
TOW2 & 786 & 397 & 514 & 420 & 391 \\
\hline
\end{tabular}

and thus were not discarded in the statistical analysis. For this reason, some stations portray slighter larger standard deviations of PWV differences between radiosonde and GPS estimates, which are not unusual.

Figure 6 shows a summary of comparison of the PWV estimates from GPS and radiosonde for each year starting from 2008 to 2012. The mean values were computed based on the average differences between radiosonde measurements of PWV with GPS, that is, "radiosonde minus GPS." The mean difference is an indication of systematic bias between the two instruments. In general, the two instruments are in good agreement with a small mean difference of less than $1 \mathrm{~mm}$. TOW2 displays the largest mean bias of $-1.5 \mathrm{~mm}$ amongst the six sites and the bias is fairly consistent across the five-year period. A closer inspection of this site revealed significant changes in the mean difference depending on the time of radiosonde launch, for example, day/night differential behavior. At 23 UTC (11 am local time), the mean difference is $-1.5 \mathrm{~mm}$, while at 11 UTC (9 pm local time), the mean difference is $0.9 \mathrm{~mm}$. This may be a result of the dry biases in the Vaisala instrumentation reported by Wang et al. [21]. The larger dry bias during daytime is primarily caused by the solar radiation heating of the humidity sensor [47].

The standard deviation can be interpreted as the spread of the PWV differences or variations from the mean. Sites showing larger variations in PWV estimates are (1) stations located in the northern part of Australia, such as DARW and TOW2, where atmospheric moisture is the highest, and (2) where the lateral distance difference between the GPS and radiosonde sites is large $(>150 \mathrm{~km})$, that is, KARR. The impact of elevation differences between radiosonde and GPS sites is negligible as there is little correlation between PWV and height differences. However the lateral separation distance of $173 \mathrm{~km}$ between KARR GPS and radiosonde site could potentially introduce errors in PWV comparisons if the two sites have very different humidity structure. Furthermore, the meteorological data used to convert GPS ZPD to PWV estimates were obtained from an AWS station, situated $45 \mathrm{~km}$ away and with stations height difference of $110 \mathrm{~m}$. The estimation of GPS PWV from KARR is therefore classified as "dubious." Glowacki et al. [22] also reported similar findings for KARR with large standard deviations using one-year data in 2000. It thus shows that it is important to colocate these stations together for meteorological monitoring purposes. The comparison statistics seem to also suggest that the extent of the standard deviations of the PWV differences is associated with the magnitude of PWV values. As the PWV estimates increase in values, so do the standard deviations of the differences between GPS and radiosonde PWV estimates. DARW and TOW2 sites show similar characteristics. A mean difference between the GPS and radiosonde PWV estimates over the 5-year period for all the sites is $0.1 \mathrm{~mm}$ with a standard deviation of $4.0 \mathrm{~mm}$.

It should be noted that the PWV estimates from ALIC station have a systematic bias of $\sim-5.0 \mathrm{~mm}$. The bias is consistent over the five-year period ranging from $-4.9 \mathrm{~mm}$ to $-5.5 \mathrm{~mm}$. The negative bias indicated that the PWV estimates from GPS are higher than those of radiosonde. This means that the radiosonde instrument at ALIC provides "dryer" PWV estimation. In fact the mean PWV differences are about two times larger than the standard deviations. Similar results were also obtained using data from 2000. This contradicts the results from Glowacki et al. [22] who used one year of data in 2000 for GPS and radiosonde PWV comparison. No systematic bias was noted in their research. Preliminary investigation seems to indicate that estimates of PWV from radiosonde underestimated our GPS derived PWV. However, when we compared our GPS tropospheric ZPD estimates to the IGS final products for the year 2000, the values are in agreement with a mean differences of $2.8 \mathrm{~mm}$ and standard deviation of $5.5 \mathrm{~mm}$. Furthermore the impact on radiosonde data of time of launch has been investigated but no correlation was found in the mean differences; that is, the bias was consistent irrespective of the time of launch. The cause of the systematic bias in PWV estimates remains unclear and requires further investigation. The mean values presented in Figure 6 have been adjusted from year to year to eliminate the systematic bias, hence a mean value of zero.

\section{Spatial Variations of PWV in Australia}

The selected eight GPS sites sample quite different climate conditions across Australia. DARW and HOB2 are located near $13^{\circ} \mathrm{S}$ and $43^{\circ} \mathrm{S}$, respectively. Most GPS sites are located relatively close to the coast with exception of ALIC GPS 

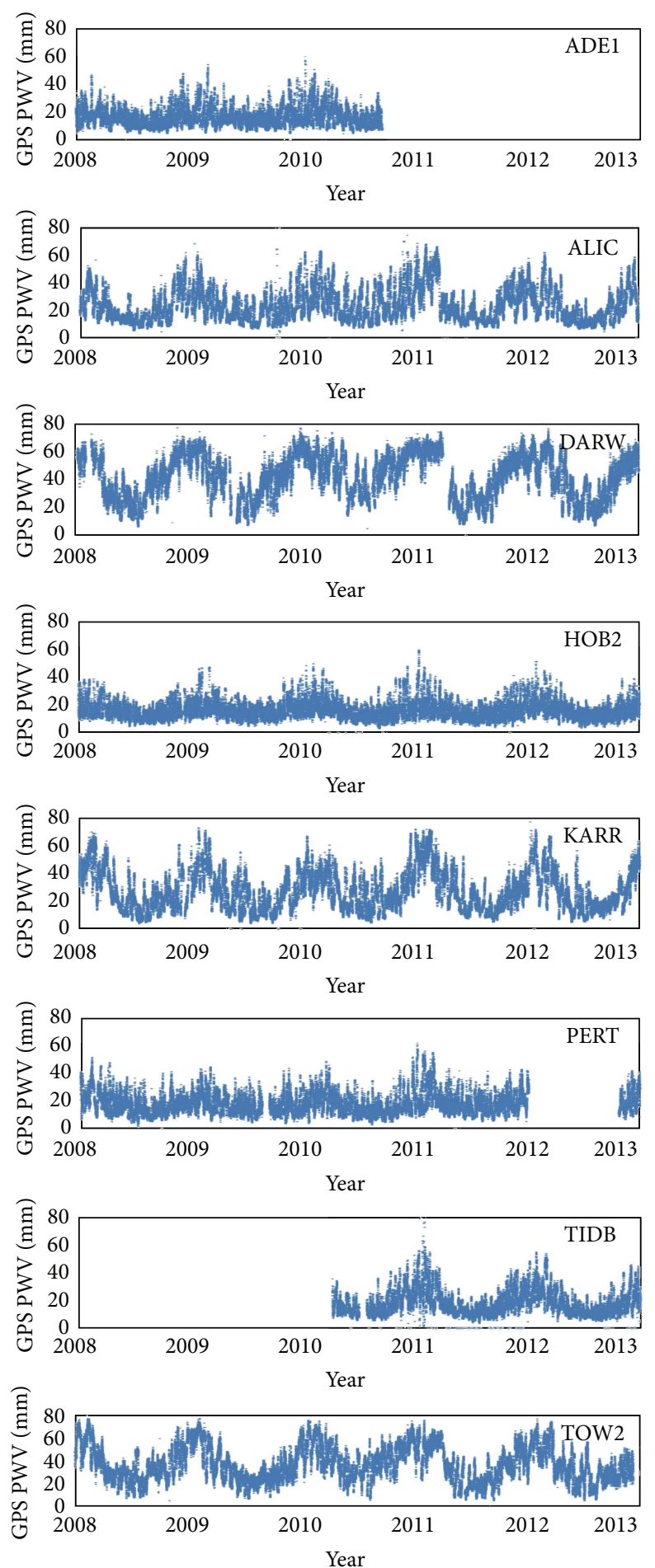

FIgURe 7: PWV estimates from 2008 to 2013 at ADE1, ALIC, DARW, HOB2, KARR, PERT, TIDB, and TOW2 GPS stations.

station (see Figure 1). The spatial and temporal variability of PWV concentration in the atmosphere depends on the season, topography, and other local/regional climate conditions. In Figure 7, the 5-year absolute PWV estimates from GPS are plotted, where available, as time series. The time series display strong annual variation in PWV at all sites, with distinctive peaks and dips occurring approximately at the austral summer and winter, respectively. The range of PWV in Australia is between $0 \mathrm{~mm}$ and $80 \mathrm{~mm}$. PWV values at stations located in the northern part of Australia, for example, DARW and TOW2, show larger variation in PWV amplitude on the basis that warm air holds more moisture and cold air is drier. The variation and magnitude of PWV are typically less at higher latitudes, for example, HOB2 with 
TABLE 7: A five-year average of GPS PWV estimates and standard deviations $(\mathrm{mm})$ at the eight GPS sites.

\begin{tabular}{lcccc}
\hline GPS site ID & Latitude & Longitude & Average $(\mathrm{mm})$ & STD $(\mathrm{mm})$ \\
\hline ADE1 & $-34.729^{\circ}$ & $138.647^{\circ}$ & 16.4 & 6.6 \\
ALIC & $-23.670^{\circ}$ & $133.886^{\circ}$ & 24.0 & 12.2 \\
DARW & $-12.844^{\circ}$ & $131.133^{\circ}$ & 42.0 & 15.4 \\
HOB2 & $-42.805^{\circ}$ & $147.439^{\circ}$ & 16.3 & 6.4 \\
KARR & $-20.981^{\circ}$ & $117.097^{\circ}$ & 29.0 & 14.3 \\
PERT & $-31.802^{\circ}$ & $115.885^{\circ}$ & 18.5 & 7.8 \\
TIDB & $-35.399^{\circ}$ & $148.980^{\circ}$ & 18.4 & 9.9 \\
TOW2 & $-19.269^{\circ}$ & $147.056^{\circ}$ & 37.1 & 15.0 \\
\hline
\end{tabular}

an average annual PWV mean of $16.3 \mathrm{~mm}$ versus DARW of $42.0 \mathrm{~mm}$. The difference in latitude between HOB2 and DARW is about $30^{\circ} \mathrm{NS}$. The variation along the longitude is not as significant as in the latitude. It is also interesting to note that the PWV at ALIC portrays fairly distinctive annual variations in comparison to $\mathrm{ADE} 1$ and $\mathrm{HOB} 2$ despite its geographical location in Central Australia, that is, inland. The latitudinal separations between those stations are between $11^{\circ}$ and $19^{\circ} \mathrm{NS}$. On the other hand, KARR and ALIC share almost similar latitudinal lines $\left(24^{\circ} \mathrm{S}\right.$ for KARR and $21^{\circ} \mathrm{S}$ for ALIC) but KARR displays higher annual variation in PWV than ALIC. This is because KARR is situated closer to the coast and coastal sites generally have higher annual variation amplitudes than sites located in the continental inland.

A 5-year average of GPS PWV estimates and standard deviation were also computed for each GPS site over period and are presented in Table 7. Comparison of the PWV averages demonstrates wide spread in values ranging from relatively dry atmosphere in the southern parts of the continent $(16.3 \mathrm{~mm}$ and $16.4 \mathrm{~mm}$ at HOB2 and ADE1, resp.) to relatively moist atmosphere in the northern parts of Australia $(37.1 \mathrm{~mm}$ and $42.0 \mathrm{~mm}$ at TOW2 and DARW, resp.). The standard deviation increases as the latitude of the station decreases. These values are typical for the Australian continent.

Figure 8 depicts contour maps showing the spatial variations of PWV in the Australian atmosphere from 2008 to 2012. The latitudinal distribution of PWV concentration is distinctive in the maps. Note that the values outside of Australia are based on extrapolation and thus should be ignored. Table 8 further tabulates the distribution of PWV as a function of latitude (with $5^{\circ}$ interval) based on Kriging interpolation method.

The Australian climate is strongly influenced by the El Niño-Southern Oscillation (ENSO) state. The ENSO is a large-scale ocean-atmosphere phenomenon that occurs across the tropical Pacific Ocean. It has two distinctly different phases, that is, warm (El Niño) and cold (La Niña) with an intervening neutral phase. During La Niña episodes, the sea surface temperatures (SSTs) in the equatorial central Pacific are cooler than normal. The pressure over Indonesia and northern Australia (e.g., in Darwin) is lower than normal and the pressure over the eastern tropical Pacific (e.g., in Tahiti) is higher than normal. Such difference in pressure distribution
TABLE 8: Average of GPS PWV estimates ( $\mathrm{mm}$ ) as a function of latitude for the Australian region.

\begin{tabular}{lccccc}
\hline \multirow{2}{*}{ Latitude } & \multicolumn{5}{c}{ Yearly average PWV $(\mathrm{mm})$} \\
& 2008 & 2009 & 2010 & 2011 & 2012 \\
\hline $5^{\circ}-10^{\circ} \mathrm{S}$ & 38 & 37 & 44 & 39 & 38 \\
$10^{\circ}-15^{\circ} \mathrm{S}$ & 36 & 36 & 41 & 37 & 36 \\
$15^{\circ}-20^{\circ} \mathrm{S}$ & 32 & 32 & 37 & 34 & 32 \\
$20^{\circ}-25^{\circ} \mathrm{S}$ & 28 & 27 & 31 & 29 & 28 \\
$25^{\circ}-30^{\circ} \mathrm{S}$ & 24 & 23 & 25 & 25 & 24 \\
$30^{\circ}-35^{\circ} \mathrm{S}$ & 20 & 21 & 20 & 21 & 21 \\
$35^{\circ}-40^{\circ} \mathrm{S}$ & 18 & 18 & 17 & 19 & 19 \\
$40^{\circ}-45^{\circ} \mathrm{S}$ & 16 & 17 & 15 & 18 & 17 \\
Average & 27 & 26 & 29 & 28 & 27 \\
\hline
\end{tabular}

is related to stronger than normal near-surface equatorial easterly winds over the central and eastern equatorial Pacific. Consequently in La Niña years, the normal patterns of atmospheric circulation and precipitation are altered.

The walker circulation, that is, a large-scale atmospheric circulation over the equatorial Pacific, which is characterized by rising air (and consequently enhanced cloudiness and higher rainfall) over the region of Indonesia and the western Pacific and sinking air (and consequently reduced cloudiness and low rainfall) over the equatorial eastern Pacific becomes stronger than normal. Concurrently, oceanic response during the La Niña episodes acts in the same direction as the atmospheric response. Cooler than normal SSTs in the equatorial central Pacific suppress the cloudiness and result in reduced rainfall in the region. At the same time, warmer than normal SSTs over northern Australia and Indonesian archipelago enhances rainfall over the Maritime continent.

Early studies on ENSO-rainfall relationship found that, in La Niña years, wetter than normal conditions develop over northern Australia, Indonesia, and Malaysia during the Austral summer (June, July, and August) [48]. Our results confirm these findings. The impact of strong 20102012 La Niña episode [49] on moisture distribution over the Australian region is clearly demonstrated in Figure 8 and Table 8. 2010 and 2011 were the third wettest and second wettest calendar years on record for Australia, with $703 \mathrm{~mm}$ and $708 \mathrm{~mm}$ of rainfall, respectively, both well above the long-term average of $465 \mathrm{~mm}$. Comparison of mean PWV over Australia for 2008 to 2012 demonstrates that moisture content in the atmosphere during La Niña years (2010-2012) was higher than that in 2008 and 2009, as summarized in Table 8 . This is in agreement with our knowledge on oceanatmosphere interaction during the ENSO cold phase, which demonstrates the potential of GPS-PWV methodology for climate research in the Australian region.

\section{Discussion and Conclusion}

GPS signals are delayed when propagating through the neutral atmosphere due to the effects of dry gases and water vapor contained in the lower atmosphere. The hydrostatic delay is a function of the surface pressure while the wet delay is a 

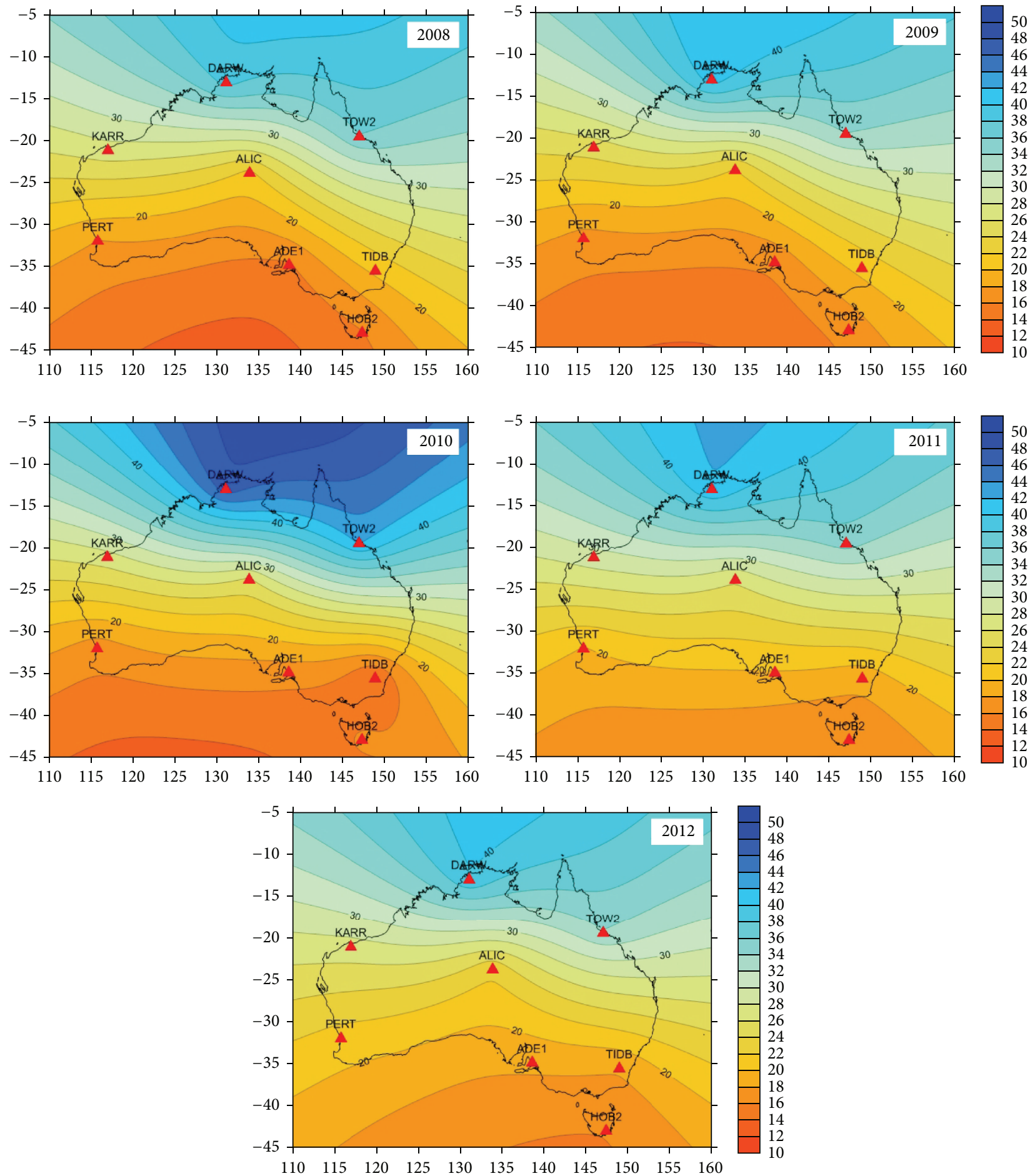

Figure 8: Distribution of mean GPS PWV (mm) over Australia from 2008 to 2012.

key parameter in atmospheric radiation, hydrological cycle, energy transfer, and the formation of clouds via latent heat [50]. Therefore, GPS derived tropospheric ZPD is a valuable parameter for studying the atmosphere, which directly or indirectly reflects the weather and climate processes $[18,50-$ 54].
This study is aimed at validating the GPS methodology for deriving time series of PWV in view of their use for climate studies and research in the Australian region. The ARGN operated and maintained by GA evolves in the 1990s primarily to serve as a national geodetic infrastructure for Australia and its territories. This infrastructure also provides 
a unique prospect to utilize the network of GPS stations for deriving atmospheric PWV. The 2011 tropospheric ZPD values computed by GA are in good agreement with the IGS final tropospheric products within $1.2 \mathrm{~mm}$ and a standard deviation of $3.6 \mathrm{~mm}$. Intertechnique comparison has been made using PWV data from eight ARGN sites over a fiveyear period from 2008 to 2012. The radiosonde datasets used in the comparison have been corrected for vertical displacement with respect to the GPS stations. VLBI data was also used at colocated Hobart GPS station. A good agreement was found with a mean difference of less than $1 \mathrm{~mm}$ and standard deviation of $3.5 \mathrm{~mm}$ between GPS and VLBI estimates and a mean difference and standard deviation of $0.1 \mathrm{~mm}$ and $4.0 \mathrm{~mm}$, respectively, for GPS and radiosonde. The accuracy of the PWV estimates can be further improved if the GPS sites are colocated with surface weather stations and radiosonde launch sites. It has also shown that the quality of the PWV estimates depends on the amount of moisture in the atmosphere, which is a function of season, topography, and other local/regional climate conditions. Standard deviations are generally larger for sites located closer to the equator and smaller in higher latitude sites. These results are consistent with previous analyses using GPS data from Australia [22, 30]. In addition, this study has revealed some systematic errors that are present in the intertechnique comparison, which further emphasizes the importance of having independent, redundant, and colocated observation sites for identification, quantification, and possible correction and calibration of systematic bias in the instruments.

A major perspective of this work is the development of a GPS processing methodology using the Australian GPS network to derive atmospheric PWV. The subsequent aim is to investigate the characteristics of long-term PWV time series over the Australian region for climate research. For the first time, we present the results of a five-year analysis of PWV from GPS, radiosonde, and VLBI for the Australian region. We have also demonstrated the promising prospects of using GPS technology for climate research in the Australia. Ground-based GPS technology offers a promising alternative PWV sensing system because of its high accuracy, high temporal resolution, and long-term stability. The next phase of this research is to study in more detail the diurnal, seasonal, and annual variations in PWV for the Australian region and subsequently long-term (over ten years) time series of PWV.

\section{Conflict of Interests}

The authors declare that there is no conflict of interests regarding the publication of this paper.

\section{Acknowledgments}

The authors would like to acknowledge Dr. Oleg Titov from the Geoscience Australia for providing the Hobart VLBI data and the IGS for providing the tropospheric products. This work was supported by the Royal Melbourne Institute of Technology (RMIT) Foundation and the Malcolm Moore Industry Research Grant.

\section{References}

[1] J. T. Kiehl and K. E. Trenberth, "Earth's annual global mean energy budget," Bulletin of the American Meteorological Society, vol. 78, no. 2, pp. 197-208, 1997.

[2] A. E. Dessler, Z. Zhang, and P. Yang, "Water-vapor climate feedback inferred from climate fluctuations, 2003-2008," Geophysical Research Letters, vol. 35, no. 20, 2008.

[3] D. L. Hoffman and A. Simmons, The Resilient Earth: Science, Global Warming and the Fate of Humanity, BookSurge Publishing, 2008.

[4] IPCC, Climate Change 2013: The Physical Science Basis. Contribution of Working Group I to the Fifth Assessment Report of the Intergovernmental Panel on Climate Change, Intergovernmental Panel on Climate Change, 2013.

[5] R. J. Ross and W. P. Elliott, "Tropospheric water vapor climatology and trends over North America: 1973-93," Journal of Climate, vol. 9, no. 12, pp. 3561-3574, 1996.

[6] J. H. Wang, H. L. Cole, and D. J. Carlson, "Performance of Vaisala RS80 radiosonde on measuring upper-tropospheric humidity after corrections," in Proceedings of the 11th Symposium on Meteorological Observations and Instrumentation, pp. 94-97, 2001.

[7] J. H. Wang, H. L. Cole, and D. J. Carlson, "Water vapor variability in the tropical western Pacific from 20-year radiosonde data," Advances in Atmospheric Sciences, vol. 18, no. 5, pp. 752766, 2001.

[8] S. A. Buehler, M. Kuvatov, V. O. John et al., "An upper tropospheric humidity data set from operational satellite microwave data," Journal of Geophysical Research: Atmospheres, vol. 113, no. 14, 2008.

[9] S. Brown, S. Desai, S. Keihm, W. Lu, and C. Ruf, "Ocean water vapor and cloud burden trends derived from the topex microwave radiometer," in Proceedings of the IEEE International Geoscience and Remote Sensing Symposium (IGARSS '07), pp. 886-889, June 2007.

[10] J. J. Simpson, J. S. Berg, C. J. Koblinsky, G. L. Hufford, and B. Beckley, "The NVAP global water vapor data set: independent cross-comparison and multiyear variability," Remote Sensing of Environment, vol. 76, no. 1, pp. 112-129, 2001.

[11] K. E. Trenberth, J. Fasullo, and L. Smith, "Trends and variability in column-integrated atmospheric water vapor," Climate Dynamics, vol. 24, no. 7-8, pp. 741-758, 2005.

[12] W. P. Elliott, "On detecting long-term changes in atmospheric moisture," Climatic Change, vol. 31, no. 2-4, pp. 349-367, 1995.

[13] M. Bevis, S. Businger, T. A. Herring, C. Rocken, R. A. Anthes, and R. H. Ware, "GPS meteorology: remote sensing of atmospheric water vapor using the global positioning system," Journal of Geophysical Research, vol. 97, no. 14, pp. 15787-15801, 1992.

[14] G. A. Hajj, E. R. Kursinski, L. J. Romans, W. I. Bertiger, and S. S. Leroy, "A technical description at atmospheric sounding by GPS occultation," Journal of Atmospheric and Solar-Terrestrial Physics, vol. 64, no. 4, pp. 451-469, 2002.

[15] S. Heise, J. Wickert, G. Beyerle et al., "Comparison of water vapor and temperature results from GPS radio occultation aboard CHAMP with MOZAIC aircraft measurements," IEEE Transactions on Geoscience and Remote Sensing, vol. 46, no. 11, pp. 3406-3411, 2008.

[16] E. R. Kursinski, G. A. Hajj, J. T. Schofield, R. P. Linfield, and K. R. Hardy, “Observing Earth's atmosphere with radio occultation 
measurements using the global positioning system," Journal of Geophysical Research D: Atmospheres, vol. 102, no. 19, pp. 2342923465, 1997.

[17] S. Jin and O. F. Luo, "Variability and climatology of PWV from global 13-year GPS observations," IEEE Transactions on Geoscience and Remote Sensing, vol. 47, no. 7, pp. 1918-1924, 2009.

[18] H. Nakamura, K. Koizumi, and N. Mannoji, "Data assimilation of GPS precipitable water vapor into the JMA mesoscale numerical weather prediction model and its impact on rainfall forecasts," Journal of the Meteorological Society of Japan, vol. 82, no. 1 B, pp. 441-452, 2004.

[19] I. D. Thomas, M. A. King, P. J. Clarke, and N. T. Penna, "Precipitable water vapor estimates from homogeneously reprocessed GPS data: an intertechnique comparison in Antarctica," Journal of Geophysical Research D: Atmospheres, vol. 116, Article ID D04107, 2011.

[20] P. Tregoning, R. Boers, D. O’Brien, and M. Hendy, “Accuracy of absolute precipitable water vapor estimates from GPS observations," Journal of Geophysical Research D: Atmospheres, vol. 103, no. 22, pp. 28701-28710, 1998.

[21] J. Wang, L. Zhang, A. Dai, T. van Hove, and J. van Baelen, "A near-global, 2-hourly data set of atmospheric precipitable water from ground-based GPS measurements," Journal of Geophysical Research D: Atmospheres, vol. 112, no. 11, Article ID D11107, 2007.

[22] T. J. Glowacki, N. T. Penna, and W. P. Bourke, "Validation of GPS-based estimates of integrated water vapour for the Australian region and identification of diurnal variability," Australian Meteorological Magazine, vol. 55, no. 2, pp. 131-148, 2006.

[23] S. H. Byun and Y. E. Bar-Sever, "A new type of troposphere zenith path delay product of the international GNSS service," Journal of Geodesy, vol. 83, no. 3-4, pp. 367-373, 2009.

[24] P. Steigenberger, V. Tesmer, M. Krügel et al., "Comparisons of homogeneously reprocessed GPS and VLBI long time-series of troposphere zenith delays and gradients," Journal of Geodesy, vol. 81, no. 6-8, pp. 503-514, 2007.

[25] S. Vey, R. Dietrich, M. Fritsche, A. Rülke, P. Steigenberger, and M. Rothacher, "On the homogeneity and interpretation of precipitable water time series derived from global GPS observations," Journal of Geophysical Research D: Atmospheres, vol. 114, no. 10, 2009.

[26] J. L. Davis, T. A. Herring, I. I. Shapiro, A. E. E. Rogers, and G. Elgered, "Geodesy by radio interferometry: effects of atmospheric modeling errors on estimates of baseline length," Radio Science, vol. 20, no. 6, pp. 1593-1607, 1985.

[27] H. S. Hopfield, "Two-quartic tropospheric refractivity profile for correcting satellite data," Journal of Geophysical Research, vol. 74, no. 18, pp. 4487-4499, 1969.

[28] J. Saastamoinen, "Contributions to the theory of atmospheric refraction," Bulletin Géodésique, vol. 46, no. 3, pp. 279-298, 1972.

[29] J. Askne and H. Nordius, "Estimation of tropospheric delay for microwaves from surface weather data," Radio Science, vol. 22, no. 3, pp. 379-386, 1987.

[30] Z. Bai, Near real-time GPS sensing of atmospheric water vapour [Ph.D. thesis], Faculty of Built Environment and Engineering, Queensland University of Technology, Brisbane, Australia, 2004.

[31] S. Hagemann, L. Bengtsson, and G. Gendt, "On the determination of atmospheric water vapor from GPS measurements," Journal of Geophysical Research: Atmospheres, vol. 108, no. 21, pp. 11-14, 2003.
[32] G. Deblonde, S. Macpherson, Y. Mireault, and P. Héroux, "Evaluation of GPS precipitable water over Canada and the IGS network," Journal of Applied Meteorology, vol. 44, no. 1, pp. 153166, 2005.

[33] P. Steigenberger, M. Rothacher, R. Dietrich, M. Fritsche, A. Rulke, and S. Vey, "Reprocessing of a global GPS network," Journal of Geophysical Research-Solid Earth, vol. 111, Article ID B05402, 2006.

[34] S. Vey, E. Calais, M. Llubes et al., "GPS measurements of ocean loading and its impact on zenith tropospheric delay estimates: a case study in Brittany, France," Journal of Geodesy, vol. 76, no. 8, pp. 419-427, 2002.

[35] P. Jarlemark, R. Emardson, J. Johansson, and G. Elgered, "Ground-based GPS for validation of climate models: the impact of satellite antenna phase center variations," IEEE Transactions on Geoscience and Remote Sensing, vol. 48, no. 10, pp. 3847-3854, 2010.

[36] H. Nakamura, H. Seko, and Y. Shoji, "Dry biases of humidity measurements fron the Vaisala RS80-A and Meisei RS291 radiosondes and from ground-based GPS," Journal of the Meteorological Society of Japan, vol. 82, no. 1, pp. 277-299, 2004.

[37] U. Hugentobler, R. Dach, P. Fridez, and M. Meindl, Eds., Bernese GPS Software Version 5.0, Astronomical Institute, University of Berne, Bern, Switzerland, 2007.

[38] IGS, International GNSS Service, http://igscb.jpl.nasa.gov/.

[39] S. M. Byram and C. Hackman, "Troposphere product by the USNO," in Proceedings of the IGS Workshop, Olsztyn, Poland, 2012.

[40] S. I. Gutman, S. R. Sahm, J. Stewart, S. Benjamin, T. Smith, and B. Schwartz, "A new composite observing system strategy for ground-based GPS meteorology," in Proceedings of the 12th Symposium on Meteorological Observations and Instrumentation, American Mathematical Society, Long Beach, Calif, USA, 2003.

[41] A. J. Coster, A. E. Niell, F. S. Solheim, V. B. Mendes, P. C. Toor, and R. B. Langley, "Effect of gradients in the GPS estimation of tropospheric water vapor," in Proceedings of the ION 53rd Annual Meeting, pp. 107-114, Albuquerque, NM, USA, July 1997.

[42] World Meteorological Organization, Methods in Use for the Reduction of Atmospheric Pressure, World Meteorological Organization, Geneva, Switzerland, 1968.

[43] M. N. Berberan-Santos, E. N. Bodunov, and L. Pogliani, "On the barometric formula inside the Earth," Journal of Mathematical Chemistry, vol. 47, no. 3, pp. 990-1004, 2010.

[44] H. Schuh, J. Boehm, G. Engelhardt et al., "Determination of tropospheric parameters within the new IVS Pilot Project," in A Window on the Future of Geodesy, vol. 128 of International Association of Geodesy Symposia, pp. 125-130, Springer, Berlin, Germany, 2005.

[45] J. E. J. Lovell, J. N. McCallum, P. B. Reid et al., "The AuScope geodetic VLBI array," Journal of Geodesy, vol. 87, no. 6, pp. 527538, 2013.

[46] A. Memmo, E. Fionda, T. Paolucci et al., "Comparison of MM5 integrated water vapor with microwave radiometer, GPS, and radiosonde measurements," IEEE Transactions on Geoscience and Remote Sensing, vol. 43, no. 5, pp. 1050-1058, 2005.

[47] H. Vömel, H. Selkirk, L. Miloshevich et al., "Radiation dry bias of the Vaisala RS92 humidity sensor," Journal of Atmospheric and Oceanic Technology, vol. 24, no. 6, pp. 953-963, 2007.

[48] C. F. Ropelewski and M. S. Halpert, "Precipitation patterns associated with the high index phase of the Southern Oscillation," Journal of Climate, vol. 2, no. 3, pp. 268-284, 1989. 
[49] BOM, An Analysis of the La Niña Life Cycle and the Impacts and Significance of the 2010-11 and 2011-12 La Niña Events in Australia, 2012, http://www.bom.gov.au/climate/enso/history/ ln-2010-12/index.shtml.

[50] S. Jin, J.-U. Park, J.-H. Cho, and P.-H. Park, "Seasonal variability of GPS-derived zenith tropospheric delay (1994-2006) and climate implications," Journal of Geophysical Research: Atmospheres, vol. 112, no. 9, 2007.

[51] S. Jade, M. S. M. Vijayan, V. K. Gaur, T. P. Prabhu, and S. C. Sahu, "Estimates of precipitable water vapour from GPS data over the Indian subcontinent," Journal of Atmospheric and SolarTerrestrial Physics, vol. 67, no. 6, pp. 623-635, 2005.

[52] Y.-A. Liou and C.-Y. Huang, "GPS observations of PW during the passage of a typhoon," Earth, Planets and Space, vol. 52, no. 10, pp. 709-712, 2000.

[53] A. Seco, P. J. González, F. Ramírez et al., "GPS monitoring of the tropical storm delta along the Canary Islands track, November 28-29, 2005," Pure and Applied Geophysics, vol. 166, no. 8-9, pp. 1519-1531, 2009.

[54] H. Seko, S. Shimada, H. Nakamura, and T. Kato, "Threedimensional distribution of water vapor estimated from tropospheric delay of GPS data in a mesoscale precipitation system of the Baiu front," Earth, Planets and Space, vol. 52, no. 11, pp. 927-933, 2000. 

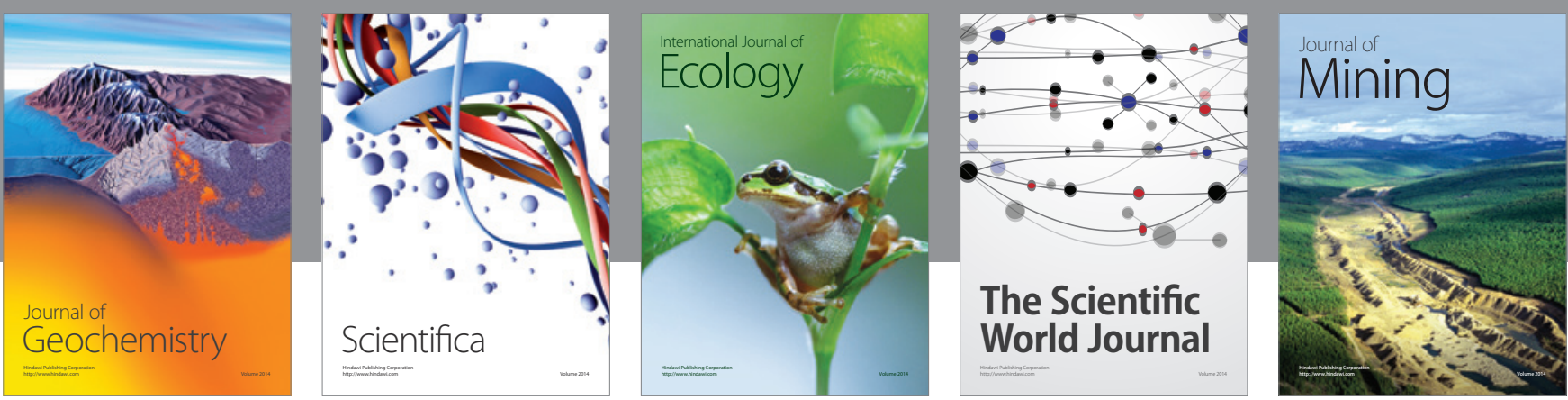

The Scientific World Journal
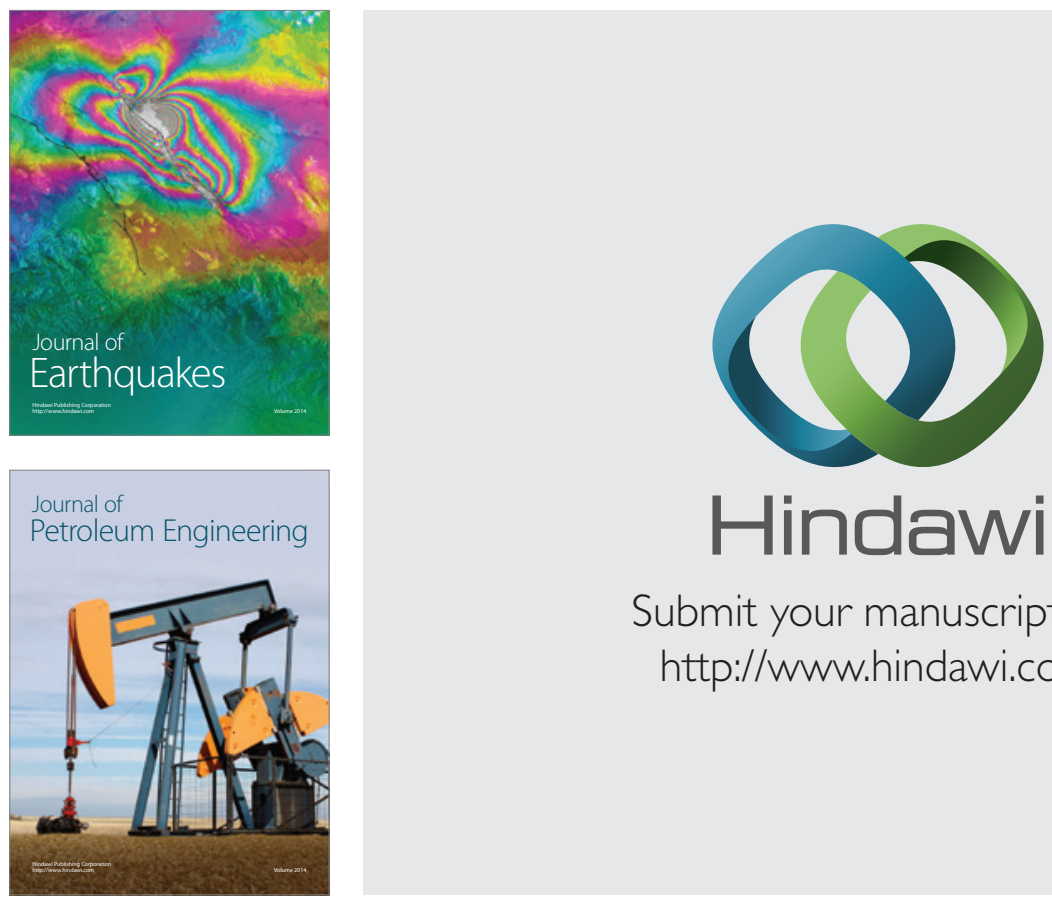

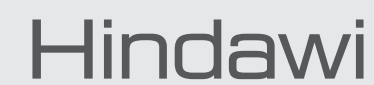

Submit your manuscripts at

http://www.hindawi.com
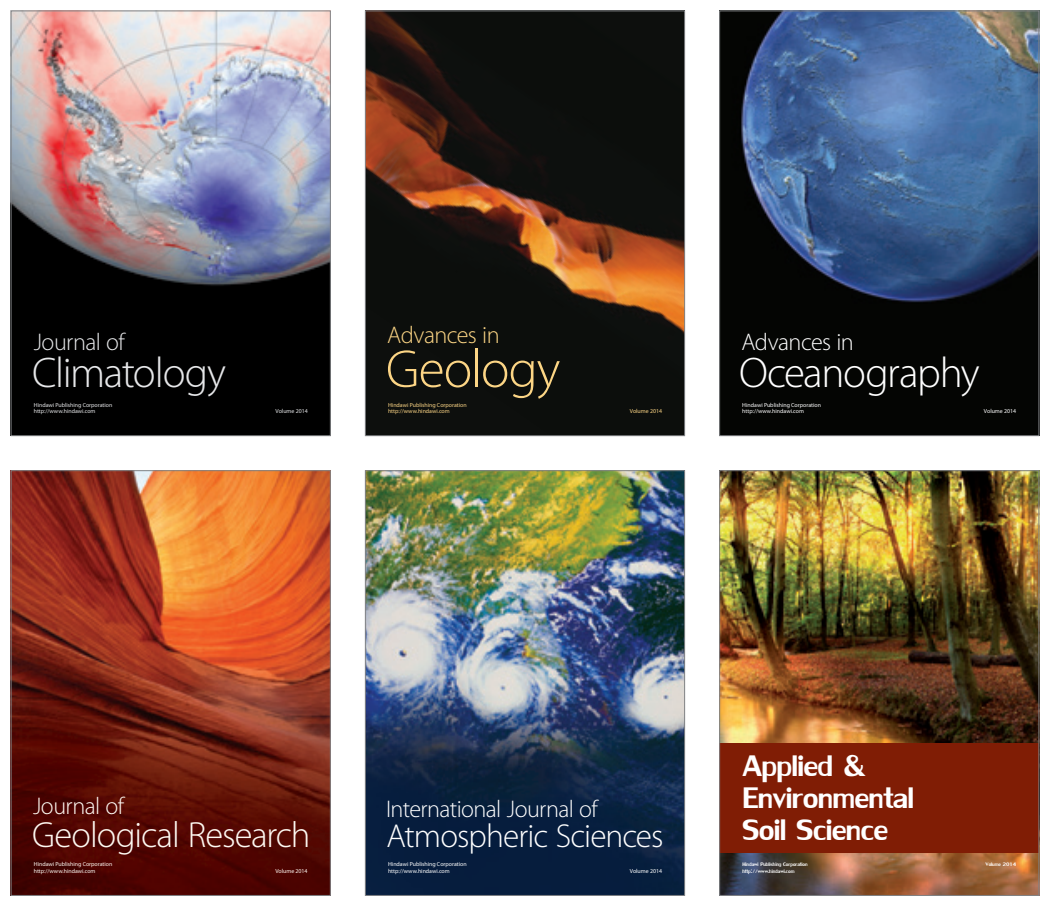
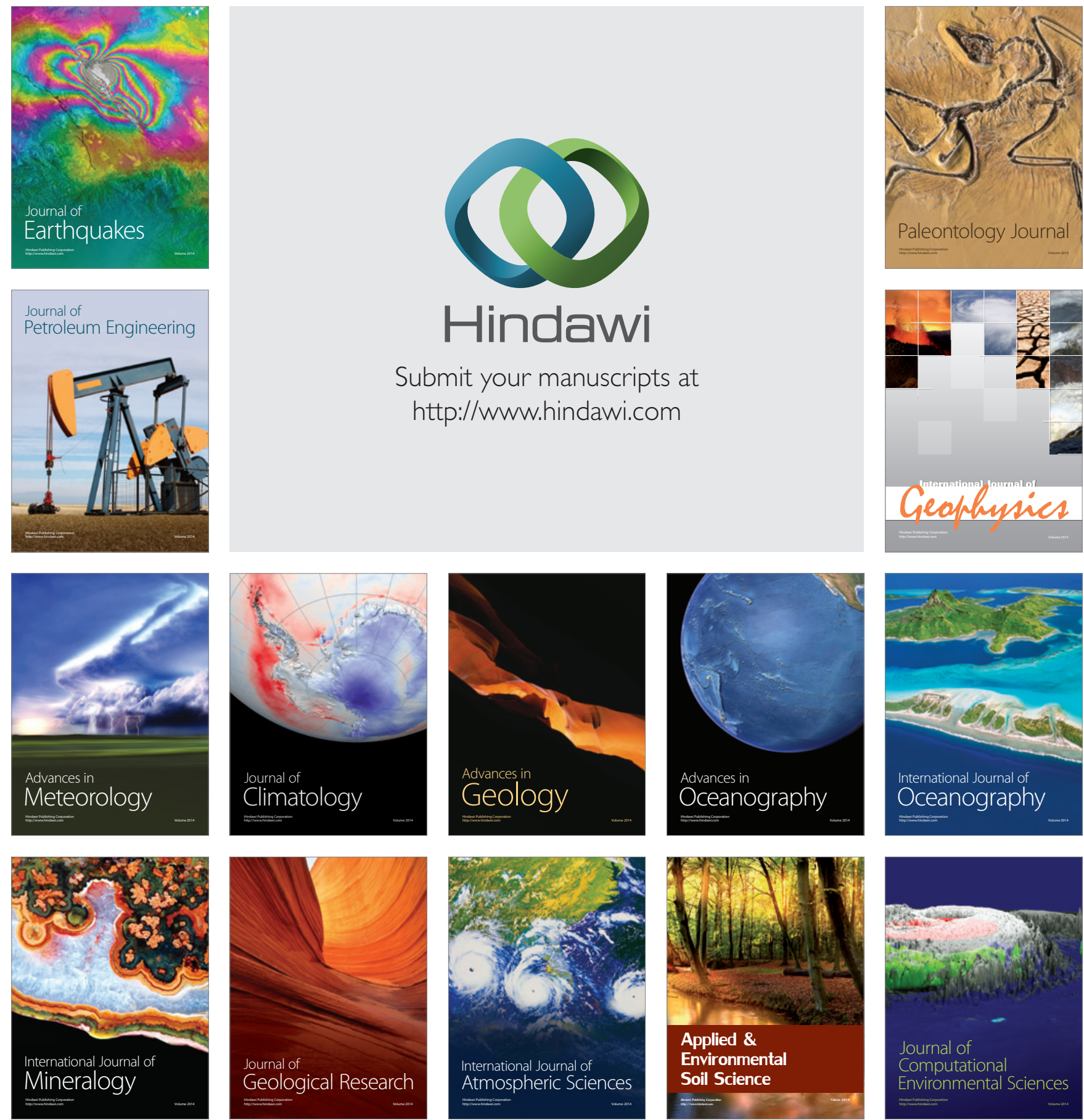